07,04

\title{
Коррелированное накопление микротрещин при ударном повреждении поверхности $\alpha$-кварца, аморфизованной имплантацией ионами $\mathrm{Ar}^{+}$
}

\author{
(c) И.П. Щербаков, А.Е. Чмель
}

Физико-технический институт им. А.Ф. Иофрфе РАН, Санкт-Петербург, Россия

ฯ E-mail: chmel@mail.ioffe.ru

Поступила в Редакцию 5 июля 2021 г.

В окончательной редакции 5 июля 2021 г.

Принята к публикации 7 июля 2021 г.

\begin{abstract}
Методом акустической эмиссии (АЭ) исследовано образование микротрещин при ударном повреждении пластин альфа кварца до и после имплантации в поверхность ионов $\mathrm{Ar}^{+}$дозами $10^{14}$ и $10^{16}$ ion $/ \mathrm{cm}^{2} \mathrm{c}$ энергией $40 \mathrm{keV}$. Статистический анализ распределений энергии во временных сериях АЭ показал, что в необлученном образце при механическом ударе имело место случайное (пуассоновского типа) накопление дефектов, характерное для разрушения однородных хрупких материалов. Распределение энергии АЭ при повреждении поверхности, имплантированной ионами, следовало степенному закону, специфичному для разрушения гетерогенных твердых тех (горные породы, керамики и т.п.). Оптическая фотография показала переход от хрупкого разрушения (до имплантации) к пластичному, вызванному нарушением связности кристаллической структуры в облученных образцах.
\end{abstract}

Ключевые слова: имплантация ионов, альфа кварц, ударное разрушение, акустическая эмиссия.

DOI: $10.21883 /$ FTT.2021.12.51675.160

\section{1. Введение}

Модификация поверхностного слоя альфа кварца ( $\alpha$-кварц) при воздействии облучения частицами (ионы, нейтроны, электроны) стала предметом многочисленных исследований во второй половине прошлого века в связи с бурным развитием микроэлектроники [1,2], и это научно-технологическое направление востребовано до настоящего времени [3], в частности, в связи c разработкой электромеханических микросенсорных устройств [4], применяемых в условиях радиации [5]. Настоящее исследование касается изменения механизма механического разрушения при ударной нагрузке $\alpha$-кварца, предварительно подвергнутого имплантации ионами $\mathrm{Ar}^{+}$. Методом акустической эмиссии (АЭ) анализировалась статистика накопления микротрещин в поверхностном слое материалыа в зависимости от дозы $(D)$ облучения.

\section{2. Образцы и оборудование}

Образцы в виде полированных пластин из кристаллического кварца, полученного гидротермальным методом имели плоскости, нормальные к оси $Z$ кристалла, которые были обработаны на линейном ускорителе дозами $10^{14}$ и $10^{16} \mathrm{ion} / \mathrm{cm}^{2} \mathrm{Ar}^{+}$с энергией $40 \mathrm{keV}$. Повреждение образцов производилось ударом груза, падающего на заостренный стальной боек, поставленный на поверхность образца. Поскольку $\alpha$-кварц обладает выраженными пьезоэлектрическими свойствами, детектором АЭ служи- ла пластина из высокочувствительной пьезокерамики $\mathrm{Pb}\left(\mathrm{Zr}_{x} \mathrm{Ti}_{1-x}\right) \mathrm{O}_{3}$, пьезоэлектрический коэффициент которой более чем на 2 порядка величины выше такового для $\alpha$-кварца. Сигналы АЭ поступали на вход аналоговоцифрового преобразователя АСК-3106 и в цифровой форме сохранялись в компьютере. Продолжительность сбора сигналов всех типов составляла $1 \mathrm{~ms}$; временное разрешение $20 \mathrm{~ns}$.

\section{3. Результаты и обсуждение}

На рис. 1 показаны временные развертки сигналов АЭ при ударе по поверхности образцов при $D=10^{14}$ и $10^{16} \mathrm{ion} / \mathrm{cm}^{2}$. Заметно, что в генерация АЭ из имплантированного слоя значительно более кратковременна, чем с нетронутой поверхности. Этот эффект можно объяснить уплотнением поверхности $\mathrm{SiO}_{2}$ и силикатных стекол при внедрении ионов [6-8], что сокращает развитие процесса повреждения. Молекулярный механизм наведенной ионами компактизации заключается в уменьшении углов $\mathrm{Si}-\mathrm{O}-\mathrm{Si}$ с образованием 3- и 4-членных силоксановых колец [9].

Энергия импульса $(E)$ пропорциональна интенсивности (квадрату амплитуды, $A^{2}$ ) сигнала АЭ. На рис. 2 приведены распределения числа импульсов в зависимости от энергии в импульсе, полученные на основе представленных на рис. 1 временных серий. Распределения построены в виде зависимостей $N(E>\varepsilon) \propto \varepsilon$, где $N-$ число импульсов, энергия которых $E$ выше величины некоторого „порога“ $\varepsilon$. 

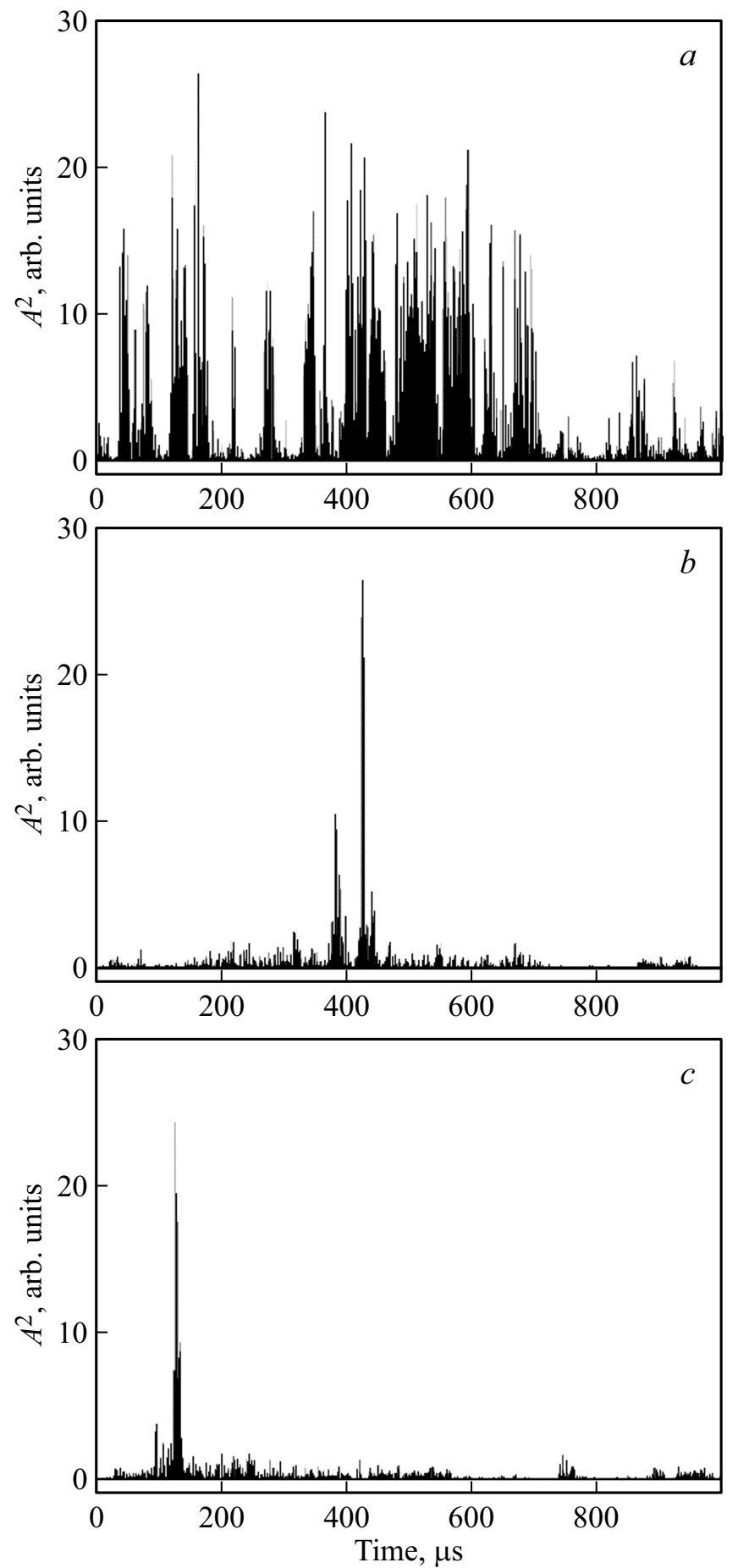

Рис. 1. Временные развертки АЭ из образца $\alpha$-кварца, стимулированные точечным ударом; $D=0(a), 10^{14}(b)$, $10^{16} \mathrm{ion} / \mathrm{cm}^{2}(c)$.

Другими словами, параметр $\varepsilon$ принимает последовательно значения энергии в зарегистрированных импульсах в интервале от 0 до $1 \mathrm{~ms}$ (горизонтальная координата), и число импульсов, энергия которых $E$ превышает текущее значение $\varepsilon$, откладывается по вертикальной оси.
Одни и те же данные построены в двух координатах полулогарифмических (рис. 2, $a, b, c)$ и двойных логарифмических (рис. 2, $d, e, f$ ). Распределение импульсов по энергиям в исходном образце $(D=0)$ представлено отрезком прямой, отвечающим соотношению

$$
\log _{10} N(E>\varepsilon) \propto-a \varepsilon,
$$

где $a-$ наклон прямой. Соотношение (1) эквивалентно экспоненциальному закону пуассоновского типа

$$
N(E>\varepsilon) \propto \exp (-a \varepsilon)
$$

который характерен для случайных событий. Зарождение микротрещин происходит независимо друг от друга, поскольку в однородном твердом теле отсутствует необходимая концентрация потенциально „слабых мест“ для взаимодействия дефектов. В двойных логарифмических координатах распределение для необлученного образца (рис. $2, d)$ не может быть выражено посредством какойлибо элементарной функции.

Иной характер распределений АЭ сигналов был найден при ударном повреждении образцов, подвергнутых ионной имплантации. В полулогарифмическом масштабе проявились сложные кривые, не имеющие semi-logпрямых участков и не отвечающих ни одной элементарной функции. В то же время, в двойных логарифмах распределения $N(E>\varepsilon)$ versus $\varepsilon$ представляют logлинейные зависимости

$$
\log _{10} N(E>\varepsilon) \propto-b \log _{10} \varepsilon
$$

Освобождаясь от логарифмов в соотношении (2), получаем распределение энергий в АЭ импульсах в форме степенного закона

$$
N(E>\varepsilon) \propto \varepsilon^{-b} .
$$

Медленно (в сравнении с экспонентой) затухающая степенная функция отражает дальние взаимодействия между микротрещинами, когда возникновение одного дефекта повышает вероятность зарождения новых дефектов в окружающих его „слабых местах“, то есть развитие повреждения происходит по кооперативному сценарию. Под действием имплантации слабые места образуются в местах разрывов кремне-кислородного каркаса, что ранее получило название „аморфизации, поверхностного слоя $\alpha$-кварца $[1,10]$. Этот термин имеет специфический характер, поскольку кристаллическое строение разрушается не возникновением беспорядочных соединений колец тетраэдров $\mathrm{SiO}_{4}$ как в структуре плавленого $\mathrm{SiO}_{2}$, а путем множественных разрывов межатомных связей. Тем самым, образуется резервуар взаимодействующих „слабых мест“, обеспечивающий кооперативное накопление микротрещин при механическом воздействии. 

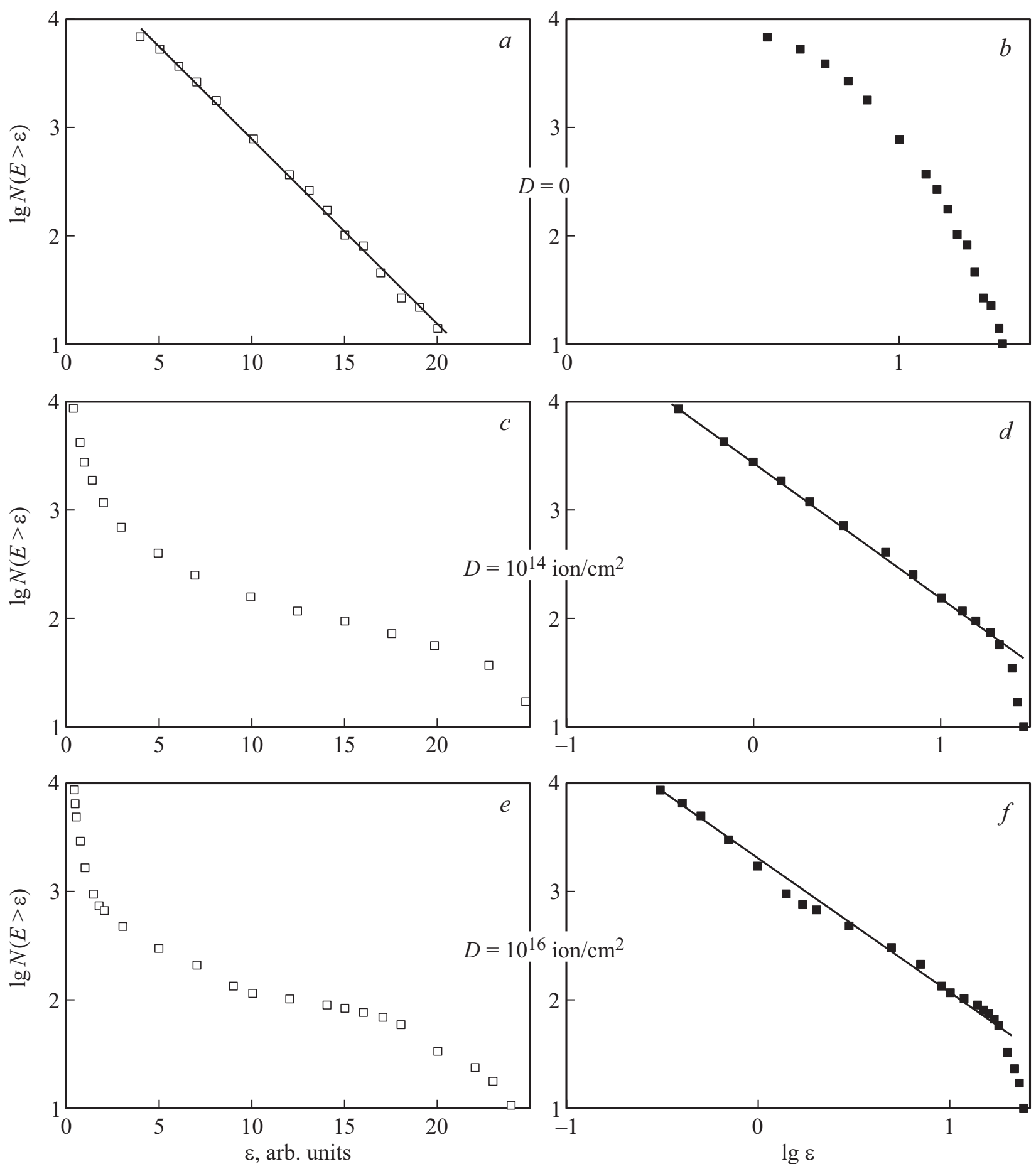

Рис. 2. Распределения энергии в импульсах АЭ, рассчитанные из временных серий, приведенных на рис. 1 ; $a, b, c-$ полулогарифмические координаты; $d, e, f$ - логарифмические координаты.

В нашем случае эффект аморфизации указанного типа проявился также в изменении морфологии разрушения. На оптической фотографии образца до имплантации (рис. $3, a$ ) точечное разрушение имеет хрупкий характер с видимыми трещинами по периметру кратера. После имплантации с дозой $10^{16} \mathrm{ion} / \mathrm{cm}^{2}$, хрупкие трещины отсутствали (рис. $3, b$ ), а кратер имеет более правиль- ную округлую форму, характерную для вязкого разрушения материала с низкой структурной связностью. Отметим, что несмотря на то, что модифицированный слой при имплантации ионов аргона в кварц составляет лишь несколько сот ангстрем [11], его наличие существенно изменило морфологию повреждения масштаба $\sim 1 \mathrm{~mm}$. 


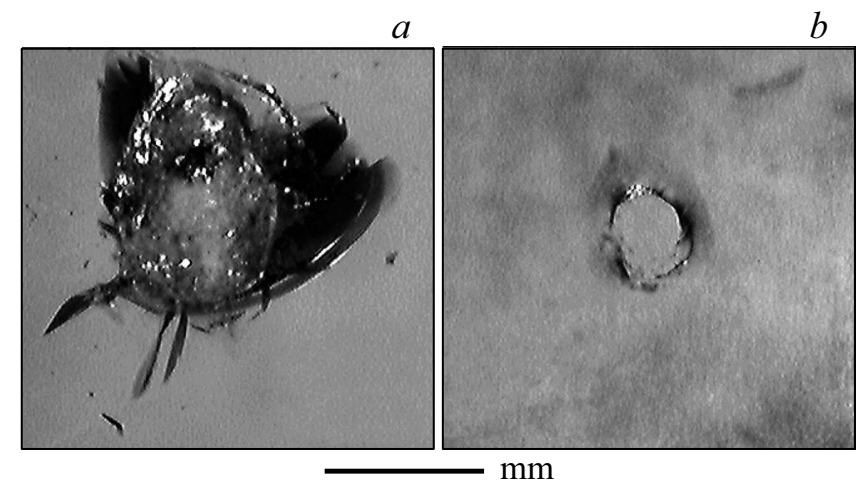

Pис. 3. Оптические фотографии повреждений поверхности образца до имплантации $(a)$ и после облучения с дозой $D=10^{16}$ ion $/ \mathrm{cm}^{2}(b)$.

\section{4. Заключение}

Имплантация инертных ионов аргона вызывает деградацию кристаллического порядка $\alpha$-кварца в виде множественных разрывов межатомных связей. Анализ произведенного механическим ударом накопления микротрещин, активных в акустической эмиссии, показал, что разрушение нарушенного облучением поверхностного слоя протекает по типу, характерному для гетерогенных материалов. Высокая концентрация атомных дефектов способствует дальнему взаимодействию растущих микротрещин, что ведет к энергетически коррелированному процессу формирования макроскопического повреждения. Несмотря на небольшую глубину пробега ионов (сотые доли микрона), морфология точечного повреждения облученной поверхности заметно отличалась от исходной.

\section{Конфликт интересов}

Авторы заявляют, что у них нет конфликта интересов.

\section{Список литературы}

[1] H. Fischer, G. Götz, H. Karge. PSS 76, 249 (1983).

[2] G.W. Arnold Nucl. Instrum. Meth. B. 65, 213 (1992).

[3] Sh. Zhou, J.W. Ju. Int. J. Damage Mech. 29, 923 (2020).

[4] B. Li, C. Li, Y. Zhao, Ch. Han, Q. Zhang. Micromashines 11, 724 (2020).

[5] B. Wang, Y. Yu, I. Pignatelli, G.N. Sant, M. Bauchy. J. Chem. Phys. 143, 024505 (2015).

[6] B. Li, X. Xiang, W. Liao, S.B. Han, J.X. Yu, X.L. Jiang, H.J. Wang, M. Mushtaq, X.D. Yuan, X.T. Zu, Y.Q. Fu. Appl. Surf. Sci. 471, 786 (2019).

[7] G. Battaglin, G.W. Arnold, G. Mattei, P. Mazzoldi. J. Appl. Phys. 85, 8040 (1999.)

[8] E. Szilágyi, I. Bányász, E. Kótai, A. Németh, C. Major, M. Fried, G. Battistig. Radiat. Eff. Defects Solids 170, 229 (2015).
[9] K. Fukumi, A. Chayahara, M. Satou, J. Hayakawa, M. Hangyo, Sh.-I. Nakashima. Jpn J. Appl. Phys. 29. Part 1, 905 (1990).

[10] L. Douillard, J.-P. Duraud. J. Phys. III France. 6, 1677 (1996).

[11] C.R. Fritzsche, W.R. Rothemund. J. Elecrochem. Soc. 119, 1243 (1972).

Редактор Д.В. Жуманов 